\section{Transplantation immunology and pathology}

Handbuch der Allgemeinen Pathologie. Volume 6, Part 8: Transplantation. Edited by J. W. Masshoff. Pp. 1070. (Springer: Berlin and New York, 1978.) DM425: \$187.

THE philosophy behind this great tome, which attempts to cover the genetic, immunological and pathological aspects of tissue and organ transplantation, is stated somewhat defensively in the preface. Thus, "The editors have often questioned the utility of this kind of review volume in a large handbook. The rapid progress of science will outstrip, as a rule. their work in cditing and preparing contributions. Whoever wants to keep abreast of recent developments will find the latest publications in scientific periodicals. The fundamental facts of contemporary knowledge, however, can only be gathered from comprehensive presentations where the widespread results are collected, compared and evaluated. Here we see the role of our volume and the reason for its publication".

To what extent have the editors and their contributors succeeded in this endeavour? Thirty authors (some better known than others, and about half from Germany or Switzerland but writing in impeccable English) have prepared 17 review chapters of variable length dealing with the genetics and chemistry of histocompatibility antigens; phylogenetic and ontogenetic aspects; the cells taking part in graft rejection and the mechanisms of rejection; tolerance (both antigen and radiation induced); graft-versus-hos: reactions: the transplantation of cells such as biood and bone marrow; the giafting of skin. cornea. connective tissue and bone; immunosuppression by antibodies; and medications and their toxicity. Some of the chapters dwell on clinical problems, and pride of place (in terms of space) is given to the general pathology of the transplantation reaction in experimental and clinical organ grafts (C. R. Jerusalem and P. H. K. Jap), a chapter that occupies roughly one-fifth of the text. Second in the pecking order is the subject of histocompatibility in the form of three chapters on the major histocompatibility system in man ( $M$. Jeannet), the lymphocyte-defined (sic) components of the major histocompatibility complex (Miriam Segall), and the biology and chemistry of major histocompatibility complex gene products (D. A. L. Davies and M. Hess).

The claim by the editors that there is a place for a book of this type is no doubt justified, for reviews are widely scattered, congress proceedings can be ephemeral and lacking in depth, and most books set themselves much more limited objectives. In judging its usefulness one would want to be satisfied that the chapters are written with authority; that the book is reasonably up to date; and that coverage of topics is sufficiently complete. I am not sure that approval can be wholly unqualified on any of these counts.

Let us take the question of coverage first. Several topics are conspicuous by their absence or treated in desultory fashion. For example, one would like to have seen chapters on in vitro correlates of graft rejection and the immunological monitoring of patients, on maternal-foetal relationships, enhancement. and the use of xenografts. One wonders whether these omissions came about by accident or design. Nor does the book emerge with full marks so far as topicality is concerned. For reasons which were at least partly beyond the control of the editors (the original editor, W. Masshoff, having died when the first manuscripts began to come in) most of the contributions are far from up to date. Thus, references to 1976 publications are rare, and even 1975 references are regrettably sparse in most chapters. As a result the reader frequently cannot escape a feeling of déjì vlt. To take but two examples: a table giving HI.A antigens and their phenotypic frequencies relies on material published in 1974, and the tentative discussion of the effects of

previous blood transfusion on the clinical outcome of kidney transplantation depends on the very earliest indications in this field.

Other criticisms of the book include the considerable and only partly unavoidable overlap between some chapters. the use by some authors of wrong (p404) or misleading (p441) terminology, the reluctance of some contributers to quote other reviews and to chance their arm in "comparing and evaluating", and the disproportionate amount of space (roughly one-fifth of the total book) taken up by the indices. mainly by an author index the value of which must be questionable. Finally, and certainly for UK readers not least, there is the absolutely prohibitive price.

It should, nevertheless, be said that research workers interested in various facets of transplantation are likely to find some parts of this book very useful. Several chapters (especially those dealing with bone marrow transplantation, pathology and graft-versus-host reactions) are magnificently illustrated, minor errors are relatively rare and the quality of paper and print is excellent. Having taken the decision to proceed with publication, the new editors (H. Cottier and E. Grundmann) have clearly worked hard and selflessly to complete an enterprise initiated by their former colleague, to whose memory the volume is dedicated.

Leslie Brent

\section{Fourier transform infrared spectroscopy}

Fourier Transform Infrared Spectroscopy: Applications to Chemical Systems. Vol. 1. Edited by J. R. Ferraro and L. J. Basile. Pp. 311. (Academic: New York, San Francisco and London, 1978.) $\$ 25 ; £ 16.25$.

INTENDED to be the first of a series on applications of Fourier transform infrared spectroscopy, this book covers topics ranging widely from polymers, to chromatography and finally to problems with nuclear reactors. Obviously, the depth of treatment is liable to be very variable, and this proves to be the case. Some of the chapters-for example, Green and Reedy on matrix isolation methods, Bates on emission spectroscopy, Griffiths on uses in conjunction with gas chromatography, and Lauer on high pressure interferometry-are quite well written and contain a fair amount of detail on both apparatus and results. The other chapters do not fit into the scheme as well: in particular, chapter 2 on applications to polymers and macromolecules, did little to show the advantage of the technique.

The book suffers from the usual problems of compilations: for example, duplication of topics. Similar remarks on the spectra of liquids occupy considerable space in chapters 5 and 6 . There are also one or two errors of fact, sometimes caused by a desire to oversell the product. Perhaps the best example of this is the statement on p 216 that "In the early 1950 s a group of investigators showed that the advantages claimed for interferometry by Fellget (1958) could be realised".

In summary, this is a useful book but I doubt whether the subject matter will casily stretch to more volumes in a series.

Geoff rey Duxbury

Geoffrey Duxbury is Lecturer in Chemical Physics at the University of Bristol, UK. 